\title{
DEMANDA DE ISCAS VIVAS PARA A FROTA ATUNEIRA CATARINENSE NA SAFRA DE 1998/99: CPUE, COMPOSIÇÃO E DISTRIBUIÇÃO DAS CAPTURAS
}

\author{
dos SANTOS, R.C. \& M. RODRIGUES-RIBEIRO \\ Centro de Ciências Tecnológicas da Terra e do Mar (CTTMar) \\ Universidade do Vale do Itajaí (UNIVALI) \\ rsclaudino@bol.com.br, ribeiro@cttmar.univali.br
}

\begin{abstract}
RESUMO
A captura de atuns e afins pelo método de vara e isca viva foi desenvolvida e é utilizada há séculos por pescadores japoneses, posteriormente adotada por açorianos e espanhóis, entre outros. A técnica consiste em pescar com vara, linha e anzol sobre cardumes que são atraídos e mantidos próximos à embarcação pelo fornecimento periódico de iscas vivas. Esta modalidade de pesca foi introduzida no Brasil ao final da década de 70 e hoje se destaca como uma das mais rentáveis do País. O objetivo geral deste trabalho foi identificar as espécies utilizadas como isca viva nesta pescaria, suas principais áreas de captura, bem como as CPUEs empregadas pela frota sobre a isca, durante a safra de 1998/99. Durante esse período foram utilizadas como isca sete espécies pertencentes às famílias Clupeidae e Engraulidae, sendo a sardinha-verdadeira (Sardinella brasiliensis) a mais importante, representando $49 \%$. A maior parte da biomassa foi capturada em intervalos de temperatura $\left(25\right.$ a $\left.28^{\circ} \mathrm{C}\right)$ e profundidade (5 a 15 metros) bem determinados, na região de Porto Belo. As CPUEs (captura por unidade de esforço) variaram entre 261,15 e $1654,3 \mathrm{Kg} / \mathrm{dia}$ de iscagem.
\end{abstract}

Palavras-chave:Isca Viva, Frota Atuneira, Sardinella brasiliensis, Santa Catarina.

\section{LIVE BAIT DEMAND OF THE TUNA FISHERY FLEET FROM SANTA CATARINA STATE (BRAZIL), ON THE 1998/99 HARVEST: CPUE, COMPOSITION AND DISTRIBUTION CATCH.}

\begin{abstract}
Tuna fishery by pole and line or baitboat was developed many years ago by Japanese fisherman. And latter incorporated by Portuguese and Spanish among others. The method consists of fishing with pole and line on tuna schools that are attracted and kept to the boat with the aid of constant thrown of live bait in the sea. This technique was firstly introduced in Brazil the seventies and nowadays is one of the most lucrative fisheries of Brazil. The main objective of this work was to identify the species which are used as live baits in this kind of fishery their main areas of capture, as well as to estimate the CPUE of the industrial fleet, on the bait stock, during the harvest period of 1998/99. Results showed that seven species of Clupeidae and Engraulidae families are used as bait, being Sardinella brasiliensis the most important specie, representing $49 \%$ in weight of total caught. Most of the biomass was captured within well delimited intervals of temperature $\left(25^{\circ} \mathrm{C}\right.$ to $\left.28^{\circ} \mathrm{C}\right)$ and depth $(5$ to $15 \mathrm{~m})$, on the Porto Belo region. CPUEs ranged between $261,15 \mathrm{e}$ $1654,3 \mathrm{Kg} /$ day of bait fishing.
\end{abstract}

Keywords: Live Bait, Tuna Fishery Fleet, Sardinella brasiliensis, Santa Catarina State. 
dos SANTOS \& RODRIGUES-RIBEIRO: Demanda de iscas vivas para a frota atuneira catarinense.

\section{INTRODUÇÃO}

A captura de tunídeos pelo método de vara e isca viva é utilizada a vários séculos por pescadores japoneses e posteriormente foi adotada por açorianos e espanhóis, entre outros. A técnica consiste em pescar com vara, linha e anzol sobre cardumes que são atraídos e mantidos próximos à embarcação pelo fornecimento periódico de iscas vivas, juvenis de pequenos peixes pelágicos, capturados previamente e acondicionados a bordo em tinas. Esta modalidade de pesca foi introduzida no Brasil ao final da década de 70 , e atualmente se destaca como uma das mais rentáveis do País, não só pela grande aceitação do atum enlatado nos mercados interno e externo, mas principalmente devido à abundância do recurso alvo, o bonito-listrado (Katsuwonus pelamis), e de sardinhas (Clupeidae) e manjubas (Engraulidae) usadas como iscas. A frota atuneira nacional cresceu rápido $e$, atualmente, o que limita o sucesso desta pescaria não é o estoque de atuns e afins, mas sim a disponibilidade das espécies pelágicas utilizadas como isca viva, capturadas com rede de cerco junto à costa, o que pode atrasar a pescaria do bonito em vários dias em função da abundância e concentração dos cardumes de isca. Entre estas espécies, destaca-se a sardinha-verdadeira (Sardinella brasiliensis), cujo estoque adulto é capturado em escala industrial e apresenta-se como o principal recurso pesqueiro do País.

No verão de 1998/99, foram monitoradas 7 embarcações da frota atuneira nacional sediada no porto pesqueiro de Itajaíl Navegantes. Foram coletados dados ambientais e de pesca, tais como temperatura, salinidade, profundidade, áreas de captura, número de dias gastos na isca, composição das espécies de isca viva e peso total das capturas de isca e bonito.

O objetivo geral deste estudo foi identificar que espécies são utilizadas como isca viva, as principais áreas de ocorrência de suas capturas, bem como as CPUEs empregadas pela frota industrial em questão sobre a isca, durante o verão de 1998/99.

\section{MATERIAL E MÉTODOS}

Para as 7 embarcações monitoradas, no decorrer de cada captura de iscas foram coletados informações sobre a profundidade, 0 tipo de cerco utilizado, a direção e intensidade do vento, a pressão atmosférica, a cobertura de nuvens, as condições do mar. No ato da captura e do transbordo também coletou-se um balde de água da superfície do mar, de onde foi medida a temperatura com um termômetro de mercúrio e retirada uma amostra de $100 \mathrm{ml}$ de água para posterior análise da salinidade em laboratório.

O peso total da captura foi obtido a partir da capacidade em peso $(\mathrm{Kg})$ e do número de saricos trazidos a bordo, foi registrada a porcentagem em número das espécies que compunham cada captura de iscas, além do comportamento e rotina dos tripulantes a bordo, no que se refere ao transporte das iscas até as áreas de captura do bonito-listrado.

\section{RESULTADOS E DISCUSSÃO}

A isca capturada foi composta por sete espécies pertencentes à ordem Clupeiformes, sendo que quatro pertencentes à família Clupeidae: sardinha-verdadeira (Sardinella brasiliensis), sardinha-cascuda (Harengula clupeola), sardinha-lage ou bandeira (Opisthonema oglinum) e sardinha-mole (Pellona harroweri); e três à família Engraulidae: boqueirão-branco (Anchoa sp.), boquerão-verde (Lycengraulis grossidens) e boqueirão bocatorta (Cetengraulis edentulus), identificados conforme Figueredo \& Menezes (1978). A espécie mais importante foi Sardinella brasiliensis, somando $49 \%$ em peso das capturas analisadas. As três espécies de Engraulidae foram agrupadas em uma categoria única, pois na maioria das amostras realizadas em campo foi impossível fazer a distinção das espécies (Figura 1). 
Foram poucos os parâmetros abióticos que mostraram alguma relação com as capturas de isca viva. Todas as capturas ocorreram em mar calmo, não foram observadas relações entre as capturas e os dados abióticos de direção e intensidade do vento, pressão atmosféri$\mathrm{ca}$, ou cobertura de nuvens. Tampouco no caso da salinidade, onde a quantidade de amostras foi insuficiente, impedindo interpretações claras.

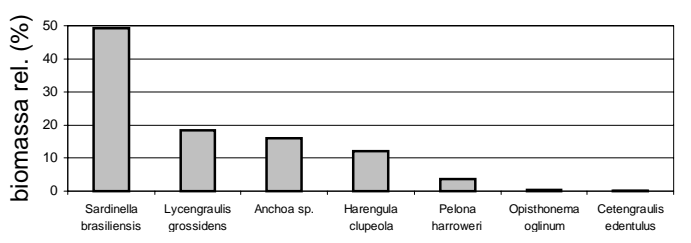

Figura 1 - freqüência de capturas por espécies

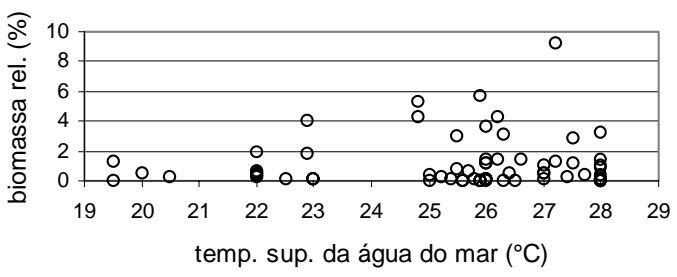

Figura 2 - distribuição das capturas (\% peso) em relaçãoà temperatura superficial de $\operatorname{mar}\left({ }^{\circ} \mathrm{C}\right)$

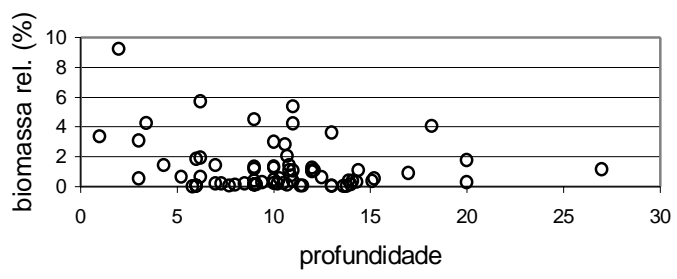

Figura 3 - distribuição das capturas (\% peso) em ralação à Profundidade local (m)

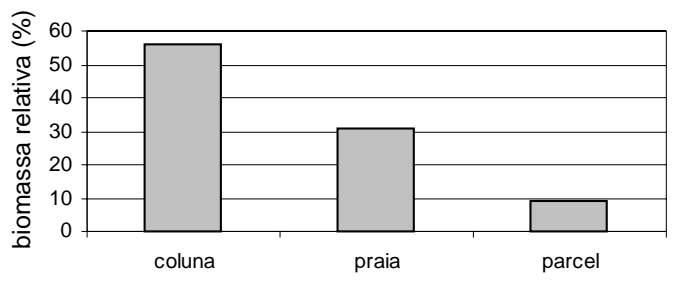

Figura 4 - distribuição das capturas (\% peso) nos três tipos de cerco identificados
O maior número de capturas, bem como as maiores biomassas individuais capturadas, ocorreram entre 25 e $28^{\circ} \mathrm{C}$ (Figura 2), e entre profundidades locais de 5 a 15 metros (Figura 3). As capturas são feitas com cercos em três locais distintos: junto a parcéis, na coluna de água e em praias. A coluna de água foi o local onde se observou a maior porcentagem em peso das capturas, cerca de 50\% (Figura 4), possivelmente refletindo uma maior eficiência do petrecho de pesca neste ambiente, bem como o maior agrupamento dos cardumes de pequenos peixes pelágicos (iscas).

As iscas estiveram presentes em áreas bem definidas. A maior porcentagem capturada em peso, por volta de $57 \%$, distribuiu-se ao redor da península que abrange os municípios de Porto Belo e Bombinhas (SC) (Figura 5), confirmando a preferência pela mesma área de captura já descrita por Lin (1992) como ÁREA 4, envolvendo as localidades de llha do Arvoredo, llha Deserta, llha da Galé , Ilha do Macuco, Santa Luzia, Canto Grande, Zimbros, Bombinhas, Bombas, Estaleiro, Praia do Cachadaço, Enseada do Araçá, Enseada de Porto Belo e Perequê. Partindo dessa classificação proposta pelo autor (ÁREA 1: Imbituba, ÁREA 2: Florianópolis, ÁREA 3: Governador Celso Ramos, ÁREA 4: Porto Belo, ÁREA 10: São Sebastião), foram determinadas as porcentagens de captura total em peso para cada área (Figura 6).

As CPUEs variaram entre 261,15 e $1654,3 \mathrm{Kg} /$ dia na isca (Figura 7), provavelmente diferenciando o poder de pesca e o cuidado das iscas a bordo, além dos distintos procedimentos de captura observados entre os mestres. Quando plotadas para cada embarcação as capturas de isca em biomassa total $(\mathrm{Kg})$ contra a CPUE ( $\mathrm{Kg} /$ dia na isca), nota-se que as embarcações que tiveram a CPUE entre 339,1 e $1329 \mathrm{Kg} /$ dia capturaram de 2568 a 3395 $\mathrm{kg}$ de isca (Figura 8). Verificou-se alguma tendência à maiores capturas de bonito estarem relacionadas às menores capturas de iscas (Figura 9). 
dos SANTOS \& RODRIGUES-RIBEIRO: Demanda de iscas vivas para a frota atuneira catarinense.

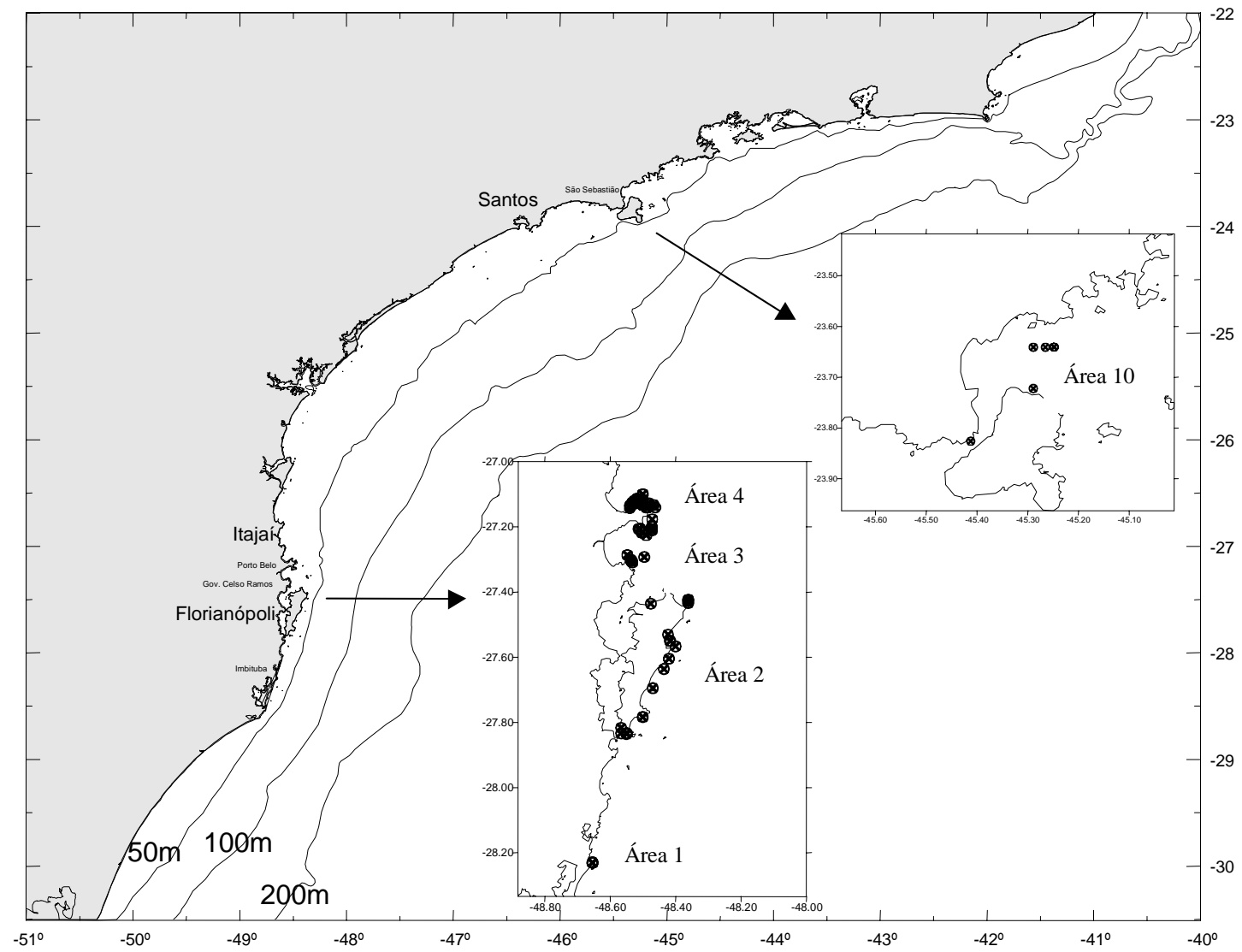

Figura 5 - áreas de capturas de iscas vivas na costa sudeste do Brasil

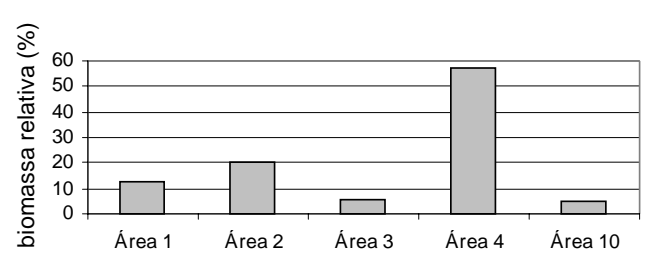

Figura 6 - distribuição das biomassas relativas (\% peso) por área

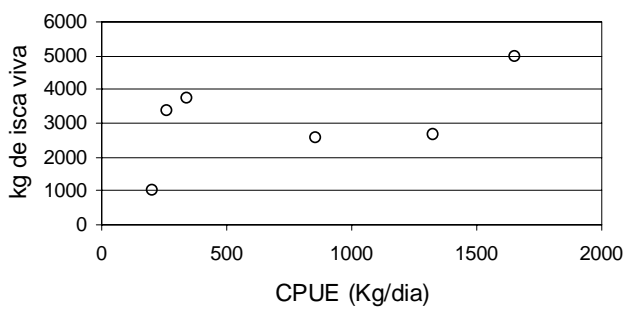

Figura 8 - distribuição das biomassas de isca-viva $(\mathrm{Kg})$, por CPUE (Kg/dia na isca)

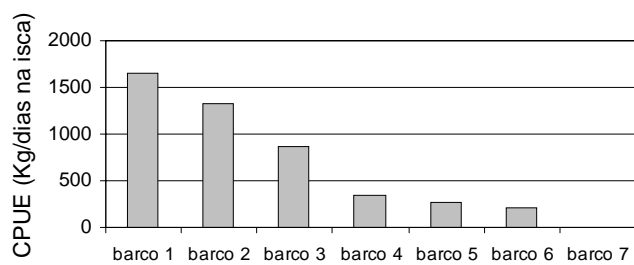

Figura 7 - CPUE para cada embarcação analizada

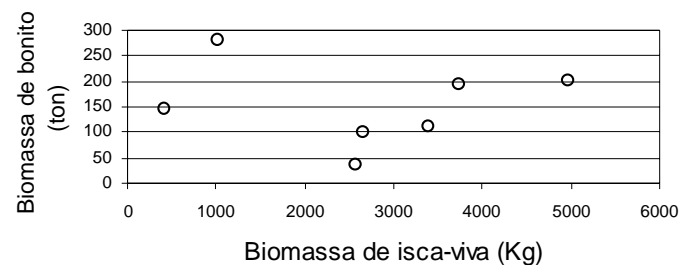

Figura 9 - distribuição das capturas de bonito (ton), por $\mathrm{Kg}$ de isca viva 


\section{CONSIDERAÇÕES FINAIS}

O universo amostral aqui analisado (7 embarcações) mostra-se insuficiente para o estabelecimento de conclusões ou padrões da pressão de pesca de iscas vivas, porém o número representou $25 \%$ da frota atuneira do Estado de Santa Catarina, composta por 28 embarcações na safra de 1999. Cabe ressaltar que no mesmo período a frota atuneira nacional foi composta por 45 embarcações, levando à porcentagem de análise para $15,5 \%$ da frota brasileira.

Durante o período amostrado a região entorno dos municípios de Porto Belo e Bombinhas, foi a mais visitada para a captura de iscas representando $60 \%$ do total capturado. As iscas utilizadas pelas embarcações, foram capturadas sem controle de tamanho, espécie ou quantidade, constando-se o domínio da espécie Sardinella brasiliensis em 49\% das capturas, esta mesma espécie exerce uma especial atração nos pescadores mesmo cercando cardumes maiores (constatação visual) de outras espécies o que pode prejudicar o recrutamento deste que é um dos principais recursos pesqueiros brasileiros.

\section{REFERÊNCIAS BIBLIOGRÁFICAS}

Figuedo, J.L. \& N.A. Menezes. 1978. Manual de peixes do Sudeste do Brasil. II Teleostei. Museu de Zoologia USP, 110p.

Lin, C.F. 1992. Atuns e afins: Estimativa da quantidade de isca viva utilizada pela frota atuneira . Ibama, 80p. 